\title{
A CHRONIC, PROGRESSIVE NEUROLOGICAL DISORDER PARKINSON'S DISEASE- MECHANISMS AND TREATMENT
}

\author{
${ }^{*}$ Dipal Patel ${ }^{1}$, Komal Sharma ${ }^{1}$, C. S. Chauhan ${ }^{1}$, Gunjan Jadon ${ }^{2}$, Twinkal Patel ${ }^{3}$ \\ ${ }^{1}$ Department of Pharmacology, B.N. Institute of Pharmaceutical Science, Udaipur (Raj.), India- 313001 \\ ${ }^{2}$ Shrinathji Institute of Pharmacy, Nathdwara, (Raj.), India- 313301 \\ ${ }^{3}$ Shri Sarvajanik Pharmacy College, Mehsana, (Guj.), India- 384001 \\ *Corresponding Author's E mail:dipalpatel786@gmail.com
}

\begin{abstract}
:
Parkinson's disease (PD) is chronic neurodegenerative disease associated with substantial morbidity. Parkinson's disease is a brain disorder that leads to shaking, stiffness, and difficulty with walking, balance, and coordination. It affects about half a million people in the United States although the numbers may be much higher. The average age of onset is 60 years, and the risk of developing Parkinson's goes up with age. Parkinson's disease was first described in 1817 by James Parkinson, a British doctor who published a paper on what he called "the shaking palsy."This article provides a brief review of the History, sign \& symptoms, Pathology \& Pathogenesis, Treatment, Herbal approaches of PD.
\end{abstract}

Keywords: Neurodegenerative disease, vascular infarctions, atherosclerosis, and vascular disease.

\section{INTRODUCTION:}

\section{Neurodegenerative Disorders}

Neurodegeneration is the umbrella term for the progressive loss of structure or function of neurons, including death of neurons. Many neurodegenerative diseases including Parkinson's, Alzheimer's, and Huntington's occur as a result of neurodegenerative processes. The generation and cell death of newly generated cells have critical roles in brain development and maintenance in the embryonic and adult brain. Alterations in these processes are also seen in neurodegenerative diseases. Genes that are key players in neurodegenerative diseases (a-synuclein, presenilin-1, tau, huntingtin) are also physiologically involved in modulating brain plasticity.

Table 1: Type of NeurodegenerationDisorders

\begin{tabular}{|l|l|l|}
\hline Condition & Pathological Markers & Main areas affected \\
\hline Alzheimer's disease & $\begin{array}{l}\text { Amyloid plaques, neurofibrillary } \\
\text { tangles }\end{array}$ & $\begin{array}{l}\text { Cerebral cortex, hippocampus, basal } \\
\text { nucleus of Meynert }\end{array}$ \\
\hline Lewy body dementia & $\begin{array}{l}\text { Lewy bodies } \\
\text { Cerebral cortex, substantianigra, basal } \\
\text { nucleus of Meynert }\end{array}$ \\
\hline Parkinson's disease & $\begin{array}{l}\text { Lewy bodies } \\
\text { vagus, basal nucleus of Meynert }\end{array}$ \\
\hline Vascular dementia & $\begin{array}{l}\text { Vascular infarctions, atherosclerosis, } \\
\text { and other markers of vascular disease }\end{array}$ & Cerebral cortex, hippocampus \\
\hline Progressive supranuclear palsy & Neurofibrillary tangles & $\begin{array}{l}\text { Cerebral cortex, basal ganglia, spinal cord, } \\
\text { midbrain }\end{array}$ \\
\hline Corticobasal degeneration & Ballooned neurons with tau inclusions & Cerebral cortex, basal ganglia \\
\hline Multiple system atrophy & Alpha-synuclein inclusions & $\begin{array}{l}\text { Hindbrain structures involved in balance } \\
\text { and autonomic functions }\end{array}$ \\
\hline
\end{tabular}

\section{Parkinson's disease}

Parkinson's disease (PD) is characterised by tremor, rigidity, bradykinesia / akinesia and loss of postural reflexes. Recently non motor symptoms of PD have been identified and sometimes they may be the only symptom at onset. Basic pathology of PD relates to dopaminergic pathway. Many secondary causes of PD are well known. ${ }^{1}$

Parkinson's disease (PD) is the most common disease of motor system degeneration and,after Alzheimer's (c) 2011, JDDT. All Rights Reserved disease, the second most common neurodegenerative disease. ${ }^{2}$ Parkinson's disease takes a heavy toll in mental anguish, lost productivity, and health care expenditures. PD prominentlyfeatures dopamine transmitter insufficiency and current management is almost exclusivelyreliant on dopamine replacement drugs. But, while these drugs are initially effective in most patients, they do not slow the underlying degeneration in the area of the brain most affected, thesubstantianigra (SN). Their effectiveness declines over time and their 
adverse effects become increasinglymore troublesome. Broader options for long-term management are urgently needed. ${ }^{3}$

\section{History: ${ }^{1}$}

In 1817 James Parkinson first described PD as "Involuntary tremulous motion, with lessened muscular power, in parts not in action and even when supported; with a propensity to bend the trunk forwards, and to pass from a walking to a running pace: the senses and intellects being uninjured" known as shaking palsy. Major criticism of this definition has been undue focus on muscle power and no importance to other symptoms like rigidity.

\section{Milestones in Parkinson's disease ${ }^{I}$}

1817- J Parkinson first described "An essay on the shaking palsy"

1841- Term 'Paralysis agitans' used for the first time by Marshall Hall

1888- Charcot referred the disease as "maladie de Parkinson" or Parkinson's disease $\mathbf{5}$

1919 - Recognised PD having cell loss in substantianigra

1939- Surgery at basal ganglia by Meyers ${ }^{6}$

1957- Carlsson and colleagues discovered dopamine ${ }^{7}$

1960- Ehringer and Hornykiewicz identified reduced dopamine in striatum 8

1961- Levodopa used for the first time in injectable form and a year later in oral form

1987- Deep-brain stimulation (DBS) was first developed in France.

\section{Signs and Symptoms of Parkinson's disease}

Parkinson's disease is common movement disorder which is characterized bythe following

* Primary motor symptoms:

- Bradykinesia(slowed movement)

- Muscle rigidity (stiffness)

- Resting tremor (shaking; usually more pronounced on one side of the body)

- Postural instability (poor balance)

* Secondary symptoms can include:

-Micrographia (small handwriting)

- Dysarthria (soft, muffled speech)

- reduced arm swing on the affected side of the body

- Short-stepped or shuffling gait

- reduced eye blinking and frequency of swallowing

- Depression and anxiety

- sleep disorders

- Low blood pressure

- Constipation
- Seborrhea (oily skin, dandruff)

\section{Major symptoms}

There are four symptoms that the majority of Parkinson's disease patients experience.

Rigidity: stiffness when an arm, leg, or the neck is moved. The muscles remain constantly tensed and contracted, so the person feels stiff and/or weak.

* Resting tremor: a tremor which occurs when the person is at rest. This often begins with an occasional trembling of one hand, most obvious when the person is at rest or under stress. In about $75 \%$ of cases, this tremor affects only one body part or side of the body initially, and then becomes more generalized over time.

* Bradykinesia: slowness in initiating movement. This may also contribute to decreased facial movement, change in speech, shuffling gait and trouble with fine-fingered movements. Many patients find this to be the most frustrating aspect of their disease. It results in a loss of independence as it progresses, due to difficulties performing everyday functions, such as getting dressed, using utensils, and rising from chairs or bed.

* Loss of postural reflexes or postural instability: resulting in poor balance and coordination. Patients sometimes develop a forward or backward lean and fall easily. This can also cause stooped posture, bowed head and drooped shoulders.

\section{Pathology \& Pathogenesis of PD}

\section{Neurochemical and Neuropathological}

The pathological hallmarks of PD are the loss of the nigrostriatal dopaminergic neurons and the presence of intraneuronalproteinacious cytoplasmic inclusions, termed "Lewy Bodies" (LBs) (Figure 1). The cell bodies of nigrostriatal neurons are in the SNpc, and they projectFamilial Neurodegenerative Diseases primarily to the putamen. The loss of these neurons, which normally contain conspicuous amounts of neuromelanin', produces the classic gross neuropathological finding of $\mathrm{SNpc}$ depigmentation (Figure 1B). The pattern of SNpc cell loss appears to parallel the level of expression of the DAtransporter (DAT) mRNA $^{10}$ and is consistent with the finding that depletion of DA is most pronounced in the dorsolateral putamen $^{11}$, the main site of projection for these neurons. At the onsets of symptoms, putamenal DA is depleted $80 \%$ and $\sim 60 \%$ of SNpc dopaminergic neurons havealready been lost. The mesolimbic dopaminergic neurons, the cell bodies of which reside adjacent to the $\mathrm{SNpc}$ in the ventral tegmental area (VTA), are much less affected in $\mathrm{PD}^{\mathbf{1 2}}$. Consequently, there is significantly less depletion of DA in the caudate ${ }^{\mathbf{1 3}}$, the main site of projection for these neurons. Neuropathological studies of PD related neurodegeneration suggest possible clues to the pathogenesis of the disease. First, PD associated loss of dopaminergic neurons has a characteristic topology, distinct from the pattern seen in normal aging. In $\mathrm{PD}$, cell loss is concentrated in ventrolateral and caudal portions of the $\mathrm{SNpc}$, whereas during normal aging the dorsomedial aspect of SNpc is affected ${ }^{14}$. Thus, 
even though age is an important risk factor for PD, the processes that produce age-related dopaminergic neuronal death are probably different from those in PD. Second, the degree of terminal loss in the striatum appears to be more pronounced than the magnitude of SNpc dopaminergic neuron loss ${ }^{11}$, suggesting that striatal dopaminergic nerve terminals are the primary target of the degenerative process and that neuronal death in PD may result from a "dying back" process. Third, the mechanism of synaptic DA clearance in the striatum seems to be more dependent on DAT than in the prefrontal cortex, where other monoaminergic transporters and the synaptic enzyme catechol- $O$ methyltransferase play a greater role in terminating the actions ofDA $15,16,17$. The prefrontal cortexis a primary site of projection for VTA dopaminergic neurons, so this difference may be of importance in understanding the relative resistance of VTA neurons to PD related degeneration. Differences in neuronal milieu have also been identified surrounding SNpc dopaminergic cell bodies. The neuropil of the substantianigra, compose of axon projections from the striatum andglobuspallidus, stains strongly for calbindin D28K, and most dopaminergic cell bodies reside within this calbin-dinrich neuropil ${ }^{18}$. However, the susceptible neurons in PD tend to be in calbindin-poor areas of the substantianigra ${ }^{19}$.

Although it is commonly thought that the neuropathology of PD is characterized solely by dopaminergic neuron loss, the neurodegeneration extends well beyond dopaminergic neurons ${ }^{20}$. Neurodegeneration and LB formation are found in noradrenergic (locus coeruleus), serotonergic (raphe), and cholinergic (nucleus basalis of Meynert, dorsal motor nucleus of vagus) systems, as well as in the cerebral cortex (especially cingulate and entorhinal cortices), olfactory bulb, and autonomic nervous system. Degeneration of hippocampal structures and cholinergic cortical inputs contribute to the high rate of dementia that accompanies $\mathrm{PD}$, particularly in older patients.

However, the clinical correlates of lesions to the serotonergic and noradrenergic pathways are not as clearly characterized as are lesions in the dopaminergic systems. Thus, while involvement of these neurochemical systems is generally thought to occurinmore severe or late-stage disease, the temporal relationship of damage to specific neurochemical systems is not well established. For example, some patients develop depression months or years prior to the onset of PD motor symptoms, which could be due to early involvement of nondopaminergic pathways. In life, the diagnosis of PD is made on clinical grounds, but definite diagnosis requires the identification of both LB and SNpc dopaminergic neuron loss. LBs are not specific for $\mathrm{PD}$, however, and are also found in $\mathrm{AD}$, in a condition called "dementia with LB disease," and as an incidental pathologic finding in people of advanced age at a greater frequency than the prevalence of PD ${ }^{\mathbf{2 1}}$. The role of LB in neuronal cell death is controversial, as are the reasons for their increased frequency in $\mathrm{AD}$ and the relationship of incidental LB to the occurrence of PD. LBs are spherical eosinophilic cytoplasmic protein aggregates composed of numerous proteins (Figure 1C), including $\alpha$-synuclein, parkin, ubiquitin, and neurofilaments, and they are found in all affected brain regions ${ }^{\mathbf{2 2 , 2 3}}$. LBs are more than $15 \mu \mathrm{m}$ in diameter and have an organized structure containing a dense hyaline core surrounded by a clear halo. Electron microscopy reveals a dense granulovesicular core surrounded by a ring of radiating $8-10 \mathrm{~nm}$ fibrils $\mathrm{s}^{\mathbf{2 4 , 2 5}}$.

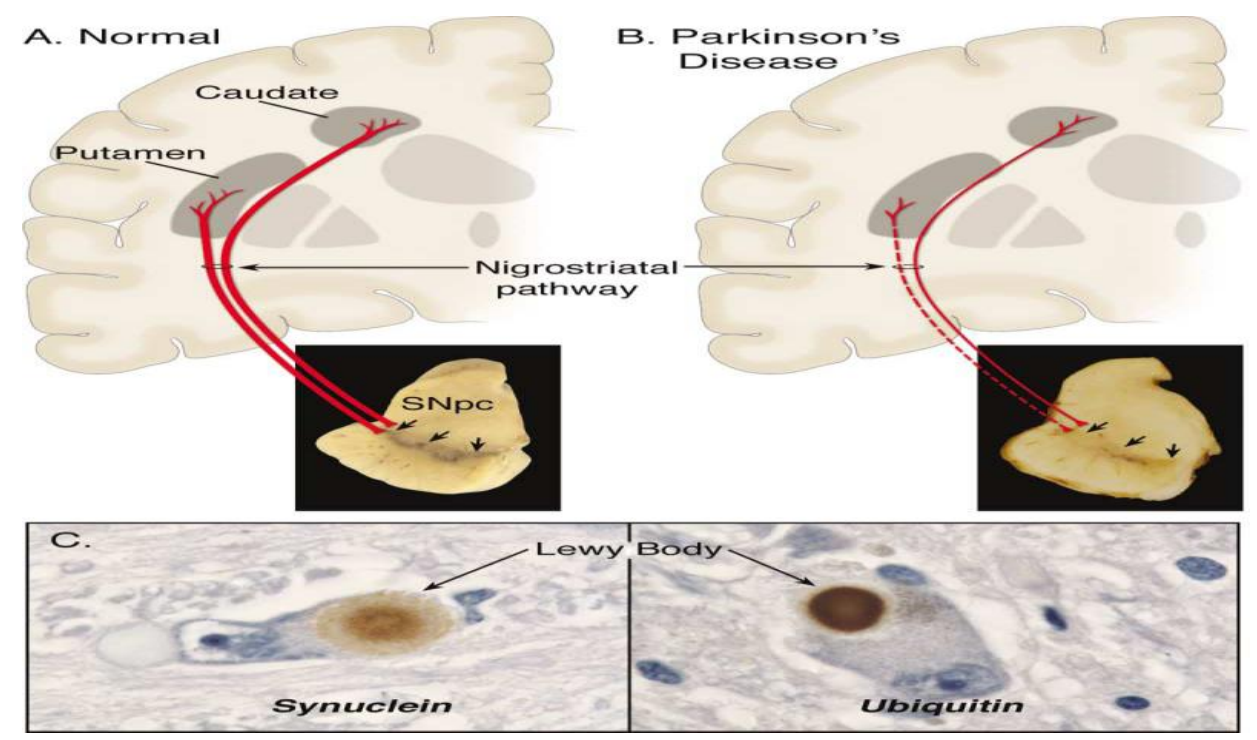

Figure 1: Neuropathology of Parkinson's disease ${ }^{9}$

(A) Schematic representation of the normal nigrostriatal pathway (in red). It is composed of dopaminergic neurons whose cell bodies are located in the substantianigra pars compacta (SNpc; see arrows). These neurons project (thick solid red lines) to the basal ganglia and synapse in the striatum (i.e., putamen and caudate nucleus). The photograph demonstrates the normal pigmentation of the SNpc, produced by neuromelanin within the dopaminergic neurons.

(B) Schematic representation of the diseased nigrostriatal pathway (in red). In Parkinson's disease, the nigrostriatal pathway degenerates. There is a marked loss of dopaminergic neurons that project to the putamen (dashed line) and a much more modest 
loss of those that project to the caudate (thin red solid line). The photograph demonstrates depigmentation (i.e., loss of dark-brown pigment neuromelanin; arrows) of the SNpc due to the marked loss of dopaminergic neurons.

(C) Immunohistochemical labeling of intraneuronal inclusions, termed Lewy bodies, in a SNpc dopaminergic neuron. Immunostaining with an antibody against $\alpha$-synuclein reveals a Lewy body (black arrow) with an intensely immunoreactive central zone surrounded by a faintly immunoreactive peripheral zone (left photograph). Conversely, immunostaining with an antibody against ubiquitin yeilds more diffuse immunoreactivity within the Lewy body (right photograph).

\section{Pathogenesis of PD}

Whatever insult initially provokes neurodegeneration, studies of toxic PD models and the functions of genes implicated in inherited forms of PD suggest two major hypotheses regarding the pathogenesis of the disease. One hypothesis posits that misfolding and aggregation of proteins are instrumental in the death of SNpc dopaminergic neurons, while the other proposes that the culprit is mitochondrial dysfunction and the consequent oxidative stress, including toxic oxidized DA species. The pathogenic factors cited above are not mutually exclusive, and one of the key aims of current PD research is to elucidate the sequence in which they act and whether points of interaction between these pathways are key to the demise of SNpc dopaminergic neurons. Potential points of interaction are diagrammed in Figure 2. The finding that oxidative damage to $\alpha$ synuclein can enhance its ability to misfold and aggregate is one example of such an interaction ${ }^{26}$. Another uncertain issue is whether the multiple cell death-related molecular pathways activated during PD neurodegeneration ultimately engage common downstream machinery, such as apoptosis, or remain highly divergent. Clearly, this issue is of great consequence in deciding about possible therapeutic strategies for PD.

\section{Misfolding and Aggregation of Proteins}

The abnormal deposition of protein in brain tissue is a feature of several age-related neurodegenerative diseases, including PD. Although the composition and location (i.e., intra- or extracellular) of protein aggregates differ from disease to disease, this common feature suggests that protein deposition per se, or some related event, is toxic to neurons.

Aggregated or soluble misfolded proteins could be neurotoxic through a variety of mechanisms. Protein aggregates could directly cause damage, perhaps by deforming the cell or interfering with intracellular trafficking in neurons. Protein inclusions might also sequester proteins that are important for cell survival. If so, there should be a direct correlation between inclusion formation and neurodegeneration. However, a growing body of evidence, particularly from studies of Huntington disease (HD) and other polyglutamine diseases $^{27,28}$, suggests that there is no correlation between inclusion formation and cell death. Cytoplasmic protein inclusions may not result simply from precipitated misfolded protein but rather from an active process meant to sequester soluble misfolded proteins from the cellular milieu ${ }^{29}$. Accordingly, inclusion formation, while possibly indicative of a cell under attack, may be a defensive measure aimed at removing toxic soluble misfolded proteins ${ }^{28,29,30,31}$. The ability of chaperones such as Hsp-70 to protect against neurodegeneration provoked by disease-related proteins (including $\alpha$ synuclein-mediated dopaminergic neuron loss) is consistent with the view that soluble misfolded proteins are neurotoxic ${ }^{33,32}$.

\section{Mitochondrial Dysfunction and Oxidative Stress}

The possibility that an oxidative phosphorylation defect plays a role in the pathogenesis of PD was fueled by the discovery that MPTP blocks the mitochondrial electron transport chain by inhibiting complex $\mathrm{I}^{34}$. Subsequent studies identified abnormalities in complex I activity in $\mathrm{PD}^{35}$. In vitro studies indicate that such a complex I defect may subject cells to oxidative stress and energy failure. The abnormality of oxidative phosphorylation identified in PD is not confined to the brain ${ }^{36}$, as reduced complex I activity has been found in platelets from PD patients ${ }^{37}$ (Parker et al., 1989) and in cybrid cells (cells lines engineered to contain mitochondria derived from platelets of PD patients ${ }^{38}$. This latter finding suggests either that the observed complex I deficit is inherited from the mitochondrial genome or that some systemic toxicity leads to mutations in mitochondrial DNA. However, mitochondrial DNA mutations have not yet been identified in PD patients.

Nearly $100 \%$ of molecular oxygen is consumed by the mitochondrial respiration, and powerful oxidants are normally produced as byproducts, including hydrogen peroxide and superoxide radicals. Inhibition of complex I increase the production of the ROS superoxide, which may form toxic hydroxyl radicals or react with nitricoxide to for mperoxynitrite. These molecules may cause cellular damage by reacting with nucleic acids, proteins, and lipids. One target of these reactive species may be the electron transport chain itself ${ }^{39}$, leading to mitochondrial damage and further production of ROS. Several biological markers of oxidative damage are elevated in the SNpc of PD brains ${ }^{40}$. Also, the content of the antioxidant glutathione is reduced in the $\mathrm{SNpc}$ of $\mathrm{PD}$ brains $^{41}$, consistent with increased ROS, although this could also indicate a primary reduction of protective mechanisms against ROS.

The presence of ROS would increase the amount of misfolded proteins, increasing the demand on the ubquitin-proteasome system to remove them. Dopaminergic neurons may be a particularly fertile environment for the generation of ROS, as the metabolism of DA produces hydrogen peroxide and superoxide radicals, and auto oxidation of DA produces DA-quinone $^{42}$, a molecule that damages proteins by reacting with cysteine residues. Mitochondria-related energy failure may disrupt vesicular storage of DA, causing the free cytosolic concentration of DA to rise and allowing harmful DA-mediated reactions to damage cellular macromolecules. Thus, DA may be pivotal in rendering SNpc dopaminergic neurons particularly 
susceptible to oxidative attack. Nevertheless, despite the literature documenting mitochondrial dysfunction and indices of oxidative damage in tissue from PD patients, all of these observations are correlative in nature, and the supportive data from are correlative in nature, and the supportive data from that such specimens primarily consist of glial cells and nondopaminergic neurons, as most dopaminergic neurons die long before these specimens become available. There are no data that convincingly link a primary abnormality of oxidative phosphorylation or ROS generation with PD. Furthermore, Parkinsonism is rare in many diseases known to result from mutations directly affecting oxidative phosphorylation ("mitochondrial cytopathies"). When Parkinsonism is encountered in these diseases, it is generally accompanied by other symptoms not typical of PD. Therefore, many of the oxidative phosphorylation and ROS abnormalities documented in PD tissues could be nonspecific features of dying cells.

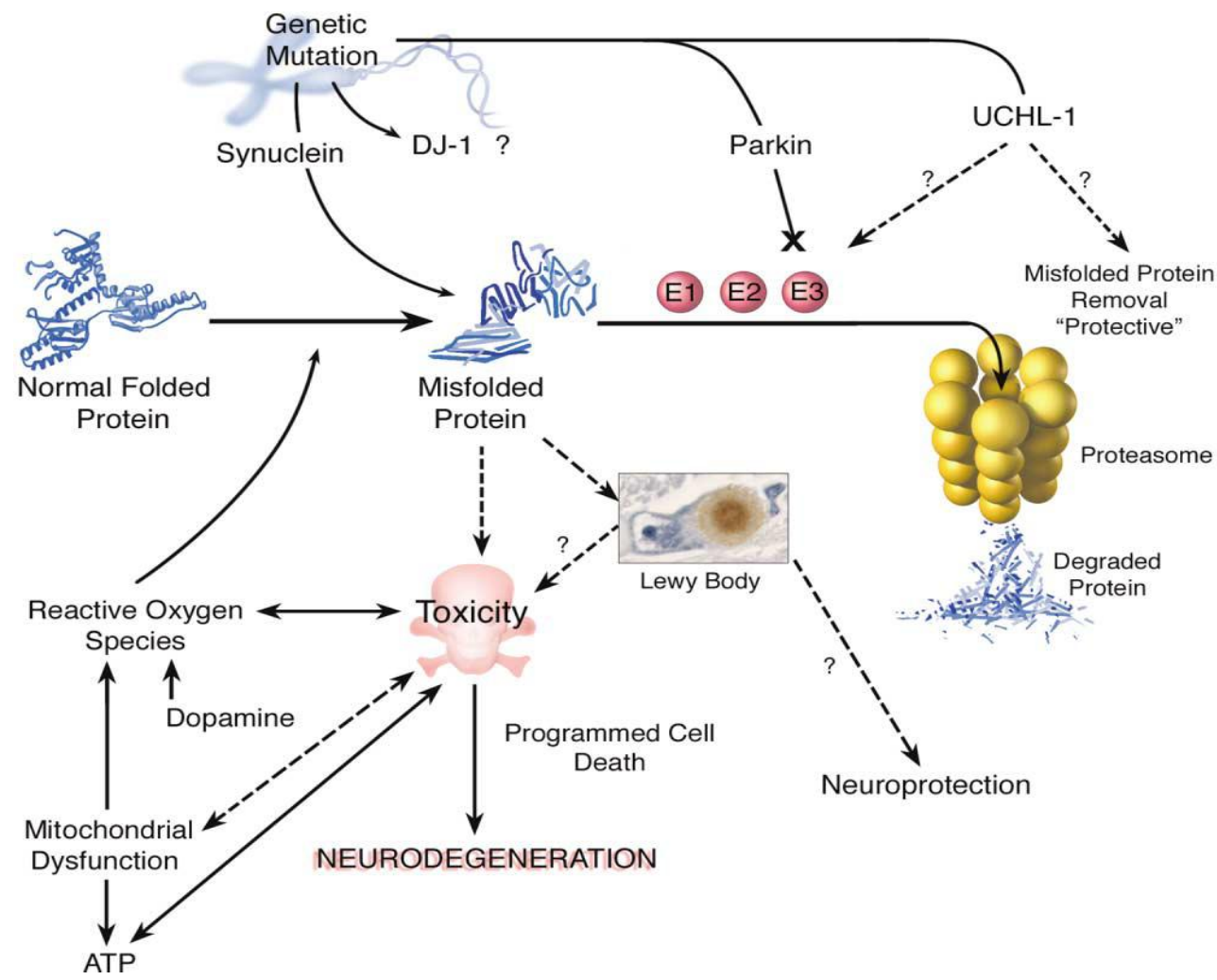

Figure 2: Mechanisms of Neurodegeneration ${ }^{26}$

A growing body of evidence, detailed in this review, suggests that the accumulation of misfolded proteins is likely to be a key event in PD neurodegeneration. Pathogenic mutations may directly induce abnormal protein conformations (as believed to be the case with $\alpha$-synuclein) or damage the ability of the cellular machinery to detect and degrade misfolded proteins; the role of DJ-1 remains to be identified. Oxidative damage, linked to mitochondrial dysfunction and abnormal dopamine metabolism, may also promote misfolded protein conformations. It remains unclear whether misfolded proteins directly cause toxicity or damage cells via the formation of protein aggregates (Lewy body). Controversy exists regarding whether Lewy bodies promote toxicity or protect a cell from harmful effects of misfolded proteins by sequestering them in an insoluble compartment away from cellular elements. Oxidative stress, energy crisis (i.e., ATP depletion) and the activation of the programmed cell death machinery are also believed to be factors that trigger the death of dopaminergic neurons in Parkinson's disease.

\section{Mode of Cell Death}

How do cells ultimately die in PD? Does a common downstream pathway mediate all PD-related cell loss, or is there significant heterogeneity in the pathways activated in different sick neurons in a single patient, or among different patients with PD? The answers to these questions are important for the rational development of therapeutic strategies for PD. In programmed cell death (PCD), intracellular signaling pathways are activated to cause cell demise. Although physiological PCD is crucial during normal development and as a homeostatic mechanism in some systems (e.g., immune system), dysregulation of this pathway in the brain may contribute to neurodegeneration. Until recently, investigators have explored the possibility that PCD occurs in PD autopsyspecimens by searching for neurons that display features of apoptosis, a morphological correlate of PCD. These morphological studies have yielded conflicting results ${ }^{\mathbf{4 3}}$. Complicating matters, if apoptosis does occur in PD, it may be difficult to detect by morphological criteria because the rate of neuronal loss may be low ${ }^{44}$ and apoptotic cells seem to disappear rapidly ${ }^{45}$. In addition, there may be nonapoptotic forms of $\mathrm{PCD}^{\mathbf{4 6 , 4 7}}$. For these reasons, some studies of PCD in PD have measured molecular components of PCD instead of relying on morphological criteria. For example, investigations of the PCD molecule Bax demonstrate an increased number of Bax-positive $\mathrm{SNpc}$ dopaminergic neurons in $\mathrm{PD}^{48}$, and compared to controls, there is 
increased neuronal expression of Bax in PD, suggesting that these cells are undergoing $\mathrm{PCD}^{\mathbf{4 9}}$. SNpc dopaminergic neurons with increased expression and subcellular redistribution of the anti-PCD protein $\mathrm{Bcl}-\mathrm{xL}$ and with activated PCD effector protease caspase- 3 have also been found in greater proportion in $\mathrm{PD}^{\mathbf{5 0 , 5 1}}$. Other molecular markers of PCD are altered in PD, including the activation of caspase- $8^{52}$ and caspase- $9^{53}$. Taken together, these studies suggest that the PCD machinery is activated in postmortem PD tissue. Nevertheless, because these studies are single time point-descriptive assessments of patient tissue they cannot address whether the findings reflect a primary abnormality of PCD regulation or an appropriate "suicide" decision by injured cells damaged by one of the processes reviewed above.

\section{Current Management of Parkinson's disease (Treatment):}

\section{Drugs}

Dopa agonists: Dopa agonists can be given orally, intravenous or as transdermal delivery system. Oral dopamine agonists are ergot and non ergot derivatives. Bromocriptine, pergolide, piribedil, pramipexole, ropinorole and dihydroergocryptine are ergot preparations and carry a risk of long term side effects in form of retroperitoneal fibrosis. Pramipexol, ropinirole and piribedil are non ergot oral preparations. Apomorphine is also nonergot and used as intravenous route. Rotigotine and lisuride are given as transdermal preparations. Dopamine receptors are classified as D1, D2, D3, D4 and D5. Most of the dopa agonist act in PD through D2 and D3 receptor activity. Bromocriptine and pergolide are having more D2 activity where as ropinirole and pramipexole are having more D3 activity. Non motor side effects are more common with dopa agonists and include edema, somnolence, constipation, dizziness, nausea and hallucinations. ${ }^{54}$

L- dopa (Dopamine precursor) Along with Decarboxylase Inhibitor : L- dopa is most important drug used in PD treatment. To prevent peripheral side effects decarboxylase inhibitor (carbidopa and benserazide) is combined with L- dopa. Nausea, vomiting and delirium are most common side effects. Tremor is least responsive symptoms. But most of the patients have significant response to the initial treatment and there is a marked relief in bradykinesia, rigidity and fatigability. However its use is limited after 5-10 years after onset of motor fluctuation.

COMT Inhibitors: Catechol-O-methyltranseferase (COMT) metabolises L- dopa to 3-O-methyldopa. COMT inhibitors block this enzyme and increase plasma half life of L-dopa. Tolcapone and entacopone are two COMT inhibitors. Entacopone is available in market in combination with L- dopa and carbidopa. Tolcapone use requires continuous monitoring for liver functions. Other side effects are related to increase dopaminergic effects including sleep disturbances.

$\underline{M A O-B \text { Inhibitors: }}:$ Selegilineand rasagiline are two MAO-B inhibitors available for commercial use. Both are irreversible inhibitors. Selegiline is used as initial treatments option however its effect has been inconsistent. Rasagiline is used in a dose of 1-2 mg/day. It is used for motor fluctuation. They should not be given with tricyclic antidepressants (TCA) and selective serotonin reuptake inhibitors (SSRI).

Amantidine:Amantidine is useful in PD and its symptoms related to dyskinesias. Mechanism of action is through N-methyl-D-aspartate(NMDA).It also has anticholinergic and dopaminomimetic action. Daily dose is $200 \mathrm{mg}-400 \mathrm{mg}$ in two divided dosages. Major side effects are headache, nausea and livedoreticularis.

Anticholinergics: Most common indication of anticholinergic drug in PD is tremor not responding to Ldopa.Usual dose is $0.5 \mathrm{mg}-6 \mathrm{mg}$ in three divided dosages. Side effects in form of psychosis are sometimes serious in elderly population.

Starting Medical Treatment in PD Patients (Dopa agonists or L-dopa): ${ }^{\mathbf{5 5}}$ There is a considerable amount of uncertainty while starting treatment for recently diagnosed patient of PD. Dopa agonists are having less motor fluctuation and have L-dopa sparing effect for initial few years of treatment. But they have some serious side effects in form of hallucinations and day time sleepiness. Their limitation is inadequate relief in motor symptoms in comparison to L-dopa. So they are considered as first line drug for young PD patients having mild symptoms and no dementia or other cognitive disorder. However they are not suitable for elderly and patients having dementia or severe motor symptoms.

Table 2: Herbal drugs used in Parkinson's disease ${ }^{56,57}$

\begin{tabular}{|l|l|l|l|l|}
\hline Plant name & Family & $\begin{array}{l}\text { Common } \\
\text { name }\end{array}$ & Mode of use & Chemical constituents \\
\hline Blepharismaderaspatensis & Acanthaceae & Nethirspoondu & Dry seed & Steroids- gomisin D \\
\hline Smilax perfoliata & Smilacaceae & Ram damtena & Dry root & Steroidal sapogeninsdiosgenin \\
\hline Smilax zeylanica & Smilacaceae & $\begin{array}{l}\text { Rough blind } \\
\text { weed,hill lotus }\end{array}$ & Dry root & Alpha, beta hydroxyl acids \\
\hline Plantagoovata & Plantaginaceae & Flax seed & Husk fibre & $\begin{array}{l}\text { Mucilage, cyano genetic } \\
\text { glycocydes- Linamarin, lotaustralin }\end{array}$ \\
\hline Azadirachtaindica & Maliaceae & Neem,margosa & Fresh leaf & $\begin{array}{l}\text { Meliacin- nimbolide, } \\
\text { quercetin, kaempferol }\end{array}$ \\
\hline Emblicaofficinalis & Euphorbiaceae & $\begin{array}{l}\text { Amla,Indian } \\
\text { goose berry }\end{array}$ & Fruit & $\begin{array}{l}\text { Tannins, Phyllembelin, } \\
\text { Pectins, Vitamin C }\end{array}$ \\
\hline
\end{tabular}




\section{CONCLUSION}

This review article provides understanding of PD pathogenesis, provided a conceptual framework for novel therapies, and spawned an accelerating research effort. The discovery of genetic causes of PD and the demonstration that dysfunction of these genes probably plays a role in sporadic PD has highlighted the importance of protein misfolding-related toxicity as a fundamental insult in neurodegeneration. The identification of PD-causing genes has also demonstrated how dysfunction of the ubiquityin-proteasome system can provoke neurodegeneration, presumably by leading to an excess of misfolded proteins.

This review article also provides understand the relationship between previously identified factors in PD neurodegeneration (e.g., mitochondrial dysfunction, ROS) and the molecular events provoked by disease alleles. A specific aspect of this work should be to clarify primary initiating events from those that may be a nonspecific consequence of neuronal demise.

\section{REFERENCES:}

1) Pandey S, Parkinson`s Disease: Recent Advances, Review Article, JAPI ,June 2012(60),30-33.

2) Saunders CD, Parkinson's disease: A New Hope. Boston, MA: Harvard Health Publications, 2000.

3) Parris MK, Parkinson's Disease as Multifactorial Oxidative Neurodegeneration: Implications for Integrative Management,Alternative Medicine Review, 2000, 5(6),502529.

4) Parkinson J, An essay on the shaking palsy. 1817. J Neuropsychiatry ClinNeurosciSpring 2002, (14), 223-36.

5) Charcot JM, Policlinique du Mardi 31 Janvier, 1888. In: Charcot J-M. Leçons du mardi à la Saltpetriere. Tome 1. Paris: La Bibliothèque des Introuvables, 2002, 199-220.

6) Meyers R. The surgery of the hyperkinetic disorders. In: Vinken PJ, Bruyn GW, eds. Handbook of clinical neurology, vol 6. Amsterdam: North Holland Publ, 1968, 844-878.

7) Bjorklund T, Carlsson T, Cederfjäll EA, Carta M, Kirik D, Optimized adeno-associated viral vector-mediated striatal DOPA delivery restores sensorimotor function and prevents dyskinesias in a model of advanced Parkinson's disease, Brain 2010,133(2), 496-511.

8) Hringer EH, Hornykiewicz O, Distribution of noradrenaline and dopamine (3-hydroxytyramine) in the human brain and their behavior in diseases of the extrapyramidal system, Parkinsonism RelatDisord, 1998, (4), 53-7.

9) Marsden CD, Neuromelanin and Parkinson's disease, J. Neural Transm, Suppl. 1983, (19), 121-141.

10) Uhl GR, Walther D, Mash D, Faucheux B, Javoy-Agid F, Dopamine transporter messenger RNA in Parkinson's disease and control substantianigra neurons. Ann. Neurol. 1994, (35), 494-498.

11) Bernheimer $H$, Birkmayer $W$, Hornykiewicz O, Jellinger $K$, Seitelberger F, Brain dopamine and the syndromes of Parkinson and Huntington. Clinical, morphological and neurochemical correlations. J. Neurol. Sci., 1973, (20), 415455.

12) Uhl, GR, Hedreen JC, Price DL,Parkinson's disease: loss of neurons from the ventral tegmental area contralateral to therapeutic surgical lesions. Neurology, 1985, (35), 12151218.

13) Price KS, Farley IJ, Hornykiewicz O, Neurochemistry of Parkinson's disease: relation between striatal and limbic dopamine. Adv. Biochem. Psychopharmacol., 1978, (19), 293-300.

14) Fearnley JM, Lees AJ, Ageing and Parkinson's disease: substantianigra regional selectivity. Brain, 1991, (114), 22832301.

15) Giros B, Jaber M, Jones SR, Wightman RM, Caron MG, Hyperlocomotion and indifference to cocaine and amphetamine in mice lacking the dopamine transporter. Nature, 1996, (379), 606-612.

16) Gogos JA, Morgan M, Luine V, Santha M, Ogawa S, Pfaff D, Karayiorgou M, Catechol-O-methyltransferase-deficient mice exhibit sexually dimorphic changes in catecholamine levels and behavior. Proc. Natl. Acad. Sci. USA, 1998, (95), 99919996.

17) Mundorf ML, Joseph JD, Austin CM, Caron MG, Wightman RM, Catecholamine release and uptake in the mouse prefrontal cortex. J. Neurochem., 2001, (79), 130-142.
18) Damier P, Hirsch EC, Agid Y, Graybiel AM, The substantianigra of the human brain. I. Nigrosomes and the nigral matrix, a compartmental organization based on calbindinD(28K) immunohistochemistry. Brain, 1999a, (122), 1421-1436.

19) Damier P, Hirsch EC, Agid Y, Graybiel AM, The substantianigra of the human brain. II. Patterns of loss of dopamine containing neurons in Parkinson's disease. Brain. 1999b, (122), 1437-1448.

20) Hornykiewicz O, Kish SJ, Biochemical pathophysiology of Parkinson's disease. In Parkinson's disease, New York: Raven Press, 1987, 19-34.

21) Gibb WR, Lees AJ, The relevance of the Lewy body to the pathogenesis of idiopathic Parkinson's disease, J. Neurol. Neurosurg. Psychiatry, 1988, (51), 745-752.

22) Forno LS, Neuropathology of Parkinson's disease, J. Neuropathol. Exp. Neurol., 1996, (55), 259-272.

23) Spillantini MG, Crowther RA, Jakes R, Hasegawa M, Goedert $\mathrm{M}, \alpha$-synuclein in filamentous inclusions of Lewy bodies from Parkinson's disease and dementia with Lewy bodies, Proc. Natl. Acad. Sci. USA, 1998, (95), 6469-6473.

24) Duffy PE, Tennyson VM, Phase and electron microscopic observations of Lewy bodies and melanin granules in the substantianigra and locus coeruleus in Parkinson's disease, J. Neuropathol. Exp. Neurol., 1965, (24), 398-414.

25) Pappolla MA, Lewy bodies of Parkinson's disease. Immune electron microscopic demonstration of neurofilament antigens in constituent filaments, Arch. Pathol. Lab. Med., 1986, (110), 1160-1163

26) Giasson BI, Duda JE, Murray IV, Chen Q, Souza JM, Hurtig HI, Ischiropoulos H, Trojanowski JQ, Lee VM, Oxidative damage linked to neurodegeneration by selective alphasynuclein nitration in synucleinopathy lesions. Science, 2000, (290), 985-989.

27) Saudou F, Finkbeiner S, Devys D, Greenberg ME, Huntingtin acts in the nucleus to induce apoptosis but death does not correlate with the formation of intranuclear inclusions. Cell, 1998, (95), 55-66.

28) Cummings CJ, Reinstein E, Sun Y, Antalffy B, Jiang Y, Ciechanover A, Orr HT, Beaudet AL, Zoghbi HY, Mutation of the E6-AP ubiquitin ligase reduces nuclear inclusion frequency while accelerating polyglutamine-induced pathology in SCA1 mice. Neuron, 1999, (24), 879-892.

29) Kopito RR, Aggresomes, inclusion bodies and protein aggregation, Trends Cell Biol, 2000, (10), 524-530.

30) Warrick JM, Chan HY, Gray-Board GL, Chai Y, Paulson HL, Bonini NM, Suppression of polyglutamine-mediated neurodegeneration in Drosophila by the molecular chaperone HSP70, Nat. Genet, 1999, (23), 425-428.

31) Cummings CJ, Sun Y, Opal P, Antalffy B, Mestril R, Orr HT, Dillmann WH, Zoghbi HY, Over-expression of inducible HSP70 chaperone suppresses neuropathology and improves motor function in SCA1 mice, Hum. Mol. Genet, 2001, (10), 1511-1518.

32) Auluck PK, Chan HY, Trojanowski JQ, Lee VM, Bonini NM, Chaperone suppression of alpha-synuclein toxicity in a Drosophila model for Parkinson's disease,Science,2002 (295), 865-868. 
33) Muchowski PJ, Protein misfolding, amyloid formation and neurodegeneration: a critical role for molecular chaperones, Neuron, 2002, (35), 9-12.

34) Nicklas WJ, Yougster SK, Kindt MV, Heikkila RE, MPTP, MPP and mitochondrial function, Life Sci., 1987, (40), 721729.

35) Greenamyre JT, Sherer TB, Betarbet R, Panov AV, Complex I and Parkinson's disease, IUBMB Life, 2001, (52), 135-141.

36) Schapira AH, Cooper JM, Dexter D, Clark JB, Jenner P, Marsden CD, Mitochondrial complex I deficiency in Parkinson's disease, J. Neurochem, 1990, (54), 823-827.

37) Parker WD, Jr.Boyson SJ, Parks JK, Abnormalities of the electron transport chain in idiopathic Parkinson's disease, Ann. Neurol, 1989, (26), 719-723.

38) Swerdlow RH, Parks JK, Miller SW, Tuttle JB, Trimmer PA, Sheehan JP, Bennett JP, Jr.Davis RE, Parker WD, Origin and functional consequences of the complex I defect in Parkinson's disease, Ann. Neurol, 1996, (40), 663-671.

39) Cohen G, Oxidative stress, mitochondrial respiration, and Parkinson's disease, Ann. N Y Acad. Sci. 2000, (899), $112-$ 120.

40) Jackson-Lewis V, Vila M, Djaldetti R, Guegan C, Liberatore G, Liu J, O’Malley KL, Burke RE, Przedborski S, Developmental cell death in dopaminergic neurons of the substantianigra of mice, J. Comp. Neurol, 2000, (424), 476488.

41) Sian J, Dexter DT, Lees AJ, Daniel S, Agid Y, Javoy-Agid F, Jenner P, Marsden CD, Alterations in glutathione levels in Parkinson's disease and other neurodegenerative disordersc affecting basal ganglia, Ann. Neurol, 1994, (36), 348-355.

42) Graham DG, Oxidative pathways for catecholamines in the genesis of neuromelanin and cytotoxic quinines, Mol. Pharmacol, 1978, (14), 633-643.

43) Przedborski S, Vila M, The 1-methy-4-phenyl-1, 2, 3, 6tetrahydropyridine mouse model. A tool to explore the pathogenesis of Parkinson's disease, Ann. N. Y. Acad. Sci., 2003, (991), 189-198.

44) McGeer PL, Itagaki S, Akiyama H, McGeer EG, Rate of cell death in Parkinsonism indicates active neuropathological process, Ann. Neurol, 1988, (24), 574-576.

45) Raff MC, Barres BA, Burne JF, Coles HS, Ishizaki Y, Jacobson MD, Programmed cell death and the control of cell survival: Lessons from the nervous system, Science, 1993, (262), 695-700.

46) Clarke PG, Apoptosis versus necrosis: In Cell Death and Diseases of the Nervous System, New Jersey: Humana Press, 1999, 3-28.
47) Sperandio S, de Belle I, Bredesen DE, An alternative, nonapoptotic form of programmed cell death, Proc. Natl. Acad. Sci. USA, 2000, (97), 14376-14381.

48) Hartmann A, Michel PP, Troadec JD, Mouatt-Prigent A, Faucheux BA, Ruberg M, Agid Y, Hirsch EC, Is Bax a mitochondrial mediator in apoptotic death of dopaminergic neurons in Parkinson's disease?, J. Neurochem, 2001a, (76), 1785-1793.

49) Tatton NA, Increased Caspase 3 and Baximmunoreactivity accompany nuclear GAPDH translocation and neuronal apoptosis in Parkinson's disease, Exp. Neurol, 2000, (166), 2943.

50) Hartmann A, Hunot S, Michel PP, Muriel MP, Vyas S, Faucheux BA, Mouatt-Prigent A, Turmel H, Srinivasan A, Ruberg M, et al., Caspase-3: A vulnerability factor and final effector in apoptotic death of dopaminergic neurons in Parkinson's disease, Proc. Natl. Acad. Sci. USA,2000, (97), 2875-2880.

51) Hartmann A, Mouatt-Prigent A, Vila M, Abbas N, Perier C, Faucheux BA, Vyas S, Hirsch EC, Increased expression and redistribution of the antiapoptotic molecule $\mathrm{Bcl}-\mathrm{xL}$ in Parkinson's disease, Neurobiol. Dis., 2002, (10), 28-32.

52) Hartmann A, Troadec JD, Hunot S, Kikly K, Faucheux BA, Mouatt-Prigent A, Ruberg M, Agid Y, Hirsch EC, Caspase- 8 is an effector in apoptotic death of dopaminergic neurons in Parkinson's disease, but pathway inhibition results in neuronal necrosis, J. Neurosci, 2001b, (21), 2247-2255.

53) Viswanath V, Wu Y, Boonplueang R, Chen S, Stevenson FF, Yantiri F, Yang L, Beal MF, Andersen JK, Caspase-9 activation results in downstream caspase- 8 activation and bid cleavage in 1-methyl-4-phenyl-1,2,3,6-tetrahydropyridineinduced Parkinson's disease, J. Neurosci., 2001, (21), 95199528.

54) Fischman AJ, Role of [18F]-dopa-PET imaging in assessing movement disorders, RadiolClin North Am, 2005, (43), 93-106.

55) Stowe RL, Ives NJ, Clarke C, van Hilten J, Ferreira J, Hawker RJ, Shah L, Wheatley K, Gray R, Dopamine agonist therapy in early Parkinson's disease, Cochrane Database Syst Rev, 2008,(2):CD006564.

56) Madhavachetty K, Sivaji K, Tulasirao K, Flowering plants of chittoor district, A.P, Students offset printers, Tirupati, 2008,(1), 350-385.

57) Asolkar LV, Kakkar KK, Chakre OJ, 2nd supp. to Glossary of Indian medicinal plants with active principles. CSIR, New Delhi, 1992, 111, 185,285. 